OPEN ACCESS

Edited by:

Amin Tamadon,

Bushehr University of Medical

Sciences, Iran

Reviewed by:

Balaji Banoth,

St. Jude Children's Research Hospital, United States

Fatemeh Maghool,

Isfahan University of Medical

Sciences, Iran

Ali Akbari,

Urmia University of Medical Sciences,

*Correspondence: Alok Raghav alokalig@gmail.com

tThese authors have contributed equally to this work

Specialty section:

This article was submitted to

Microbial Immunology,

a section of the journal

Frontiers in Microbiology

Received: 26 July 2021 Accepted: 26 August 2021 Published: 11 October 2021

Citation:

Raghav A, Ali SG, Jeong G-B, Gautam KA, Banday S, Mateen QN,

Tripathi P, Giri R, Agarwal S, Singh $M$ and Khan HM (2021) Newer Horizon of Mesenchymal Stem CellBased Therapy in the Management of

SARS-CoV-2-Associated Mucormycosis: A Safe Hope for Future Medicine.

Front. Microbiol. 12:738983.

doi: 10.3389/fmicb.2021.738983

\section{Newer Horizon of Mesenchymal Stem Cell-Based Therapy in the Management of SARS-CoV-2- Associated Mucormycosis: A Safe Hope for Future Medicine}

\author{
Alok Raghav ${ }^{1 *}$, Syed Ghazanfar Ali ${ }^{2 \dagger}$, Goo-Bo Jeong ${ }^{3 \dagger}$, Kirti Amresh Gautam ${ }^{1}$, \\ Shahid Banday , Qazi Noorul Mateen ${ }^{5}$, Prashant Tripathi ${ }^{6}$, Richa Giri ${ }^{7}$, Saurabh Agarwal ${ }^{7}$, \\ Manish Singh ${ }^{8}$ and Haris M. Khan ${ }^{2}$

\begin{abstract}
${ }^{1}$ Multidiscplinary Research Unit, Department of Health Research, MoHFW, GSVM Medical College, Kanpur, India, '2Viral Research Diagnostic Laboratory, Department of Microbiology, Jawaharlal Nehru Medical College and Hospital, Aligarh Muslim University, Aligarh, India, ${ }^{3}$ Department of Anatomy and Cell Biology, College of Medicine, Gachon University, Getbeol-ro Yeonsu-gu, Incheon, Korea, ${ }^{4}$ Department of Molecular, Cell and Cancer Biology, University of Massachusetts Medical School, Worcester, MA, United States, ${ }^{5}$ Department of Biochemical Engineering and Biotechnology, Indian Institute of Technology Delhi, New Delhi, India, ${ }^{6}$ Department of Biochemistry, GSVM Medical College, Kanpur, India, ${ }^{7}$ Department of Medicine, GSVM Medical College, Kanpur, India, ${ }^{8}$ Department of Neurosciences, GSVM Medical College, Kanpur, India
\end{abstract}

SARS-CoV-2-infected patients are reported to show immunocompromised behavior that gives rise to a wide variety of complications due to impaired innate immune response, cytokine storm, and thrombo-inflammation. Prolonged use of steroids, diabetes mellitus, and diabetic ketoacidosis (DKA) are some of the factors responsible for the growth of Mucorales in such immunocompromised patients and, thus, can lead to a life-threatening condition referred to as mucormycosis. Therefore, an early diagnosis and cell-based management cosis is the need of the hour to help affected patients overcome this severe condition. In addition, extended exposure to antifungal drugs/therapeutics is found to initiate hormonal and neurological complications. More recently, mesenchymal stem cells (MSCs) have been used to exhibit immunomodulatory function and proven to be beneficial in a clinical cell-based regenerative approach. The immunomodulation ability of MSCs in mucormycosis patient boosts the immunity by the release of chemotactic proteins. MSC-based therapy in mucormycosis along with the combination of short-term antifungal drugs can be utilized as a prospective approach for mucormycosis treatment with promising outcomes. However, preclinical and in mucormyln mucormycosis, the hyphae of clinical trials are needed to establish the precise mechanism of MSCs in mucormycosis treatment.

Keywords: mesenchymal stem cells, Mucormycosis, SARS-CoV-2, COVID-19, immunomodulation 


\section{INTRODUCTION}

Mesenchymal stromal cells (MSCs) are multipotent adult stem cells that exhibit their presence in several tissues, including bone marrow, umbilical cord, and fat tissues. These cells differentiate into multiple tissues, such as bone, cartilage, connective tissue, muscle, and fat cells (Krampera, 2011). The International Society of Cellular Therapy (ISCT) defines MSCs as cells that (i) should be plastic adherent in defined standard culture medium and conditions; (ii) tend to differentiate in vitro into adipocytes, osteoblasts, and chondroblasts; and last (iii) should express immunophenotypic markers, including CD73, CD90, and CD105 except for CD14, CD34, CD45, and class II major histocompatibility complex molecules (Dominici et al., 2006; Figure 1). MSCs play a significant role in regulating $\mathrm{T}$ cell subsets, B cells, natural killer (NK) cells, neutrophils, and monocyte-derived cells as these exhibit the characteristics to interact with the immune system (Bernardo and Fibbe, 2013). MSCs are also involved in imparting tissue repair and regeneration (Li et al., 2021; Raghav et al., 2021). MSCs are currently being explored as a novel therapeutic approach in various clinical settings. MSC transplantation is known to provide a regenerative effect and tissue repair in several organ systems, including the central nervous system (CNS), heart, skin, and bone (Hashemian et al., 2021; Liu and Holmes, 2021).

MSCs exhibit immunomodulatory function and prove to be beneficial in clinical cell-based regenerative approaches. The U.S. Food and Drug Administration (FDA) conducted 950 successful clinical trials over 10,000 subjects performing promising MSC therapies (Pittenger et al., 2019). MSCs possess immunosuppressive characteristics and can be effectively used for the treatment of autoimmune diseases (Li et al., 2021). Moreover, several clinical results reflect a promising effect of MSCs in various diseases; however, the antimicrobial properties of MSCs are still a concern of research in clinical settings. Published research has found that transplantation of hematopoietic stem cells (HSCs) possessing immunosuppressive capabilities shows inhibition of antimicrobial immune responses that report increased risk of infection in immunocompromised individuals (Nauta and Fibbe, 2007). In another study conducted on MSCs, it is demonstrated that MSCs mediate immunosuppression in the fungal infected subject (Le Blanc et al., 2008). In a related study, it is found that the gamma/ delta $\mathrm{T}$ cells produce IL-17, which exhibits an antifungal effect

Abbreviations: SARS-CoV-2, Severe Acute Respiratory Syndrome Coronavirus 2; MSCs, Mesenchymal Stromal Cells; COVID-19, Coronavirus Disease-19; CD, Complementary Determining; ISCT, International Society of Cellular Therapy; NK cells, Natural Killer Cells; CNS, Central Nervous System; USA, United States of America; FDA, Food and Drug Administration; HSC, Hematopoietic Stem Cells; IL-6, Interleukin -6; DM, Diabetes Mellitus; DKA, Diabetic Ketoacidosis; ROCM, Rhino-Orbital-Cerebral Mucormycosis; TLR-2, Toll-Like Receptors 2; CT, Computerized Tomography; RHS, Reverse Halo Sign; PET/CT, Positron Emission Tomography-Computed Tomography; FDG, fluorodeoxyglucose; RFLP, Restriction Fragment Length Polymorphism Analyses; MALDI-TOF MS, Matrix-Assisted Laser Desorption Ionization-Time of Flight Mass Spectrometry; muMSCs, Murine Mesenchymal Stem Cells; AML, Acute Myeloid Leukemia; TNF- $\alpha$, Tumor Necrosis Factor- $\alpha$; BAM, Bronchial Alveolar Macrophages; PDGF RB, plaTelet-Derived Growth Factor Receptor B; PMNs, Polymorphonuclear Leukocytes; hBMSCs, Human Bone Marrow Derived Stem Cells.
(Caccamo et al., 2011). This antifungal mechanism contributes to increased expression of Th17 levels through the infusion of IL 17+ MSCs in mice infected with C. albicans (Caccamo et al., 2011).

In SARS-CoV-2-recovered subjects, post COVID-19 sepsis is among the common complications. The post-COVID-19 irregularities include impaired innate immune response, cytokine storm, thrombo-inflammation, and eventual immune exhaustion. Mucormycosis contributes to life-threatening fungal infections with higher than $50 \%$ mortality rates even postsurgical debridement and after antifungal drugs (Johnson et al., 2021). Recently, several cases of mucormycosis in patients infected with SARS-CoV-2 have been reported worldwide with significant numbers in India. The leading causes that facilitate Mucorales spores to germinate in SARS-CoV-2-infected patients include hypoxia, hyperglycemia (new-onset, steroid-induced, and diabetes mellitus or DM), low $\mathrm{pH}$ (diabetic ketoacidosis or DKA and metabolic acidosis), increased iron levels, and impaired phagocytic activities of white blood cells contributed by immunosuppression (steroid mediated; Figure 2). These factors, along with prolonged hospitalization with and without mechanical ventilators, contribute to the significant increase in mucormycosis cases.

In around $70 \%$ of mucormycosis cases, rhizopusarrhizus is the culprit fungus responsible for causing pulmonary, gastric, cutaneous, and rhino-orbital-cerebral diseases, especially in adults (Johnson et al., 2021). The high pathogenicity of this fungus contributes to rapid tissue obliteration and invasion throughout tissue planes (Ibrahim and Kontoyiannis, 2013). These SARS-CoV-2-recovered patients are at higher risk of developing mold infections, such as mucormycosis, due to the application of prolonged corticosteroids and anti-IL-6-directed approaches. The present review is focused on the therapeutic aspect of MSCs in these mold-infected patients. Moreover, the pathogenesis, diagnosis, clinical features, and management of mucormycosis is also described in detail.

\section{SARS-COV-2-ASSOCIATED COMORBIDITIES}

The disease pattern in SARS-CoV-2-infected patients ranges from mild to severe bacterial- and fungal-associated pneumonia (Farnoosh et al., 2020). Several associated comorbidities (DM, chronic obstructive pulmonary disease) and immunocompromised conditions (prolonged corticosteroid therapy, period of stay in intensive care unit, ventilation) put the patient's life at risk of developing opportunistic infections. Recently, several opportunistic infections, including oropharyngeal candidiasis, pulmonary aspergillosis, pneumocystis jiroveci, and bloodstream candida infections are seen in patients infected with SARS-CoV-2 (Chowdhary et al., 2020; Salehi et al., 2020). Rhino-orbital-cerebral-mucormycosis (ROCM) refers to the sino-nasal, rhino-orbital, and rhino-orbital-cerebral disease, among the most common in current clinical practices worldwide. A few cases have been reported recently in patients infected with SARS-CoV-2 (Mehta and Pandey, 2020; Mekonnen et al., 2020). In a similar trend, six cases of ROCM were also reported recently in COVID-19 disease (Sen et al., 2021). Among these six cases, one patient had concurrent COVID-19 


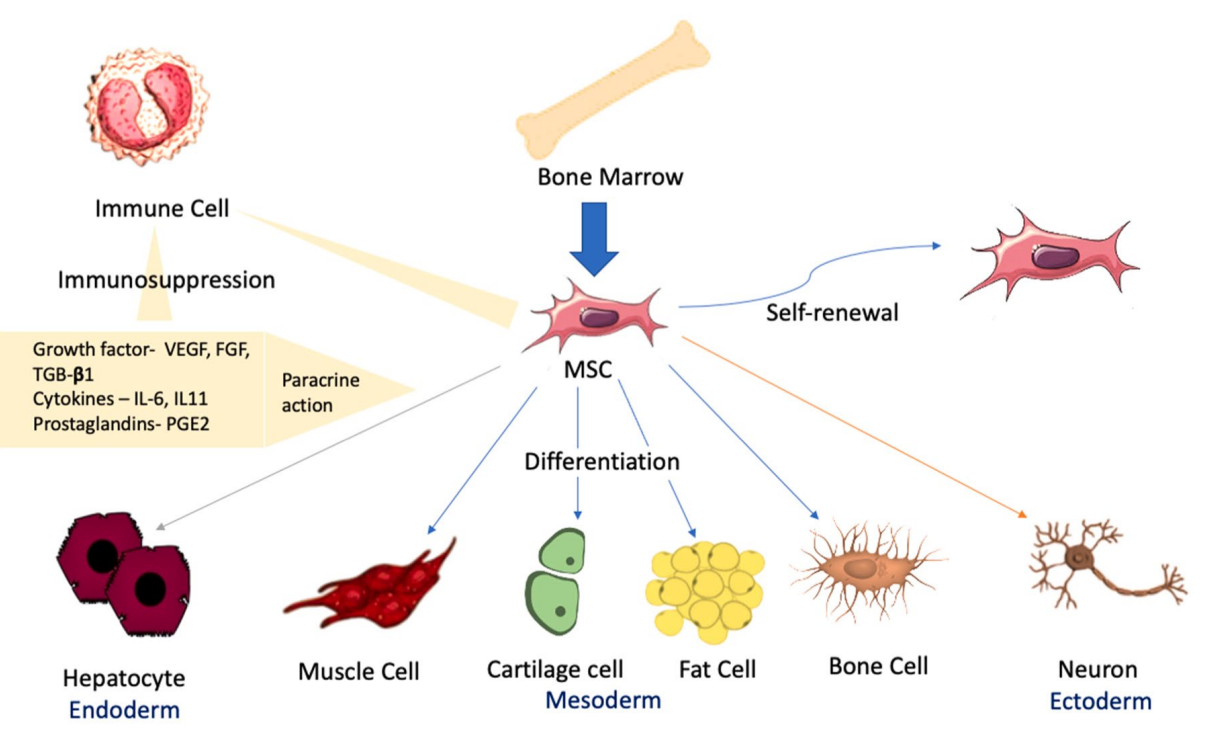

FIGURE 1 | The differentiation of MSCs into various organs and tissues.

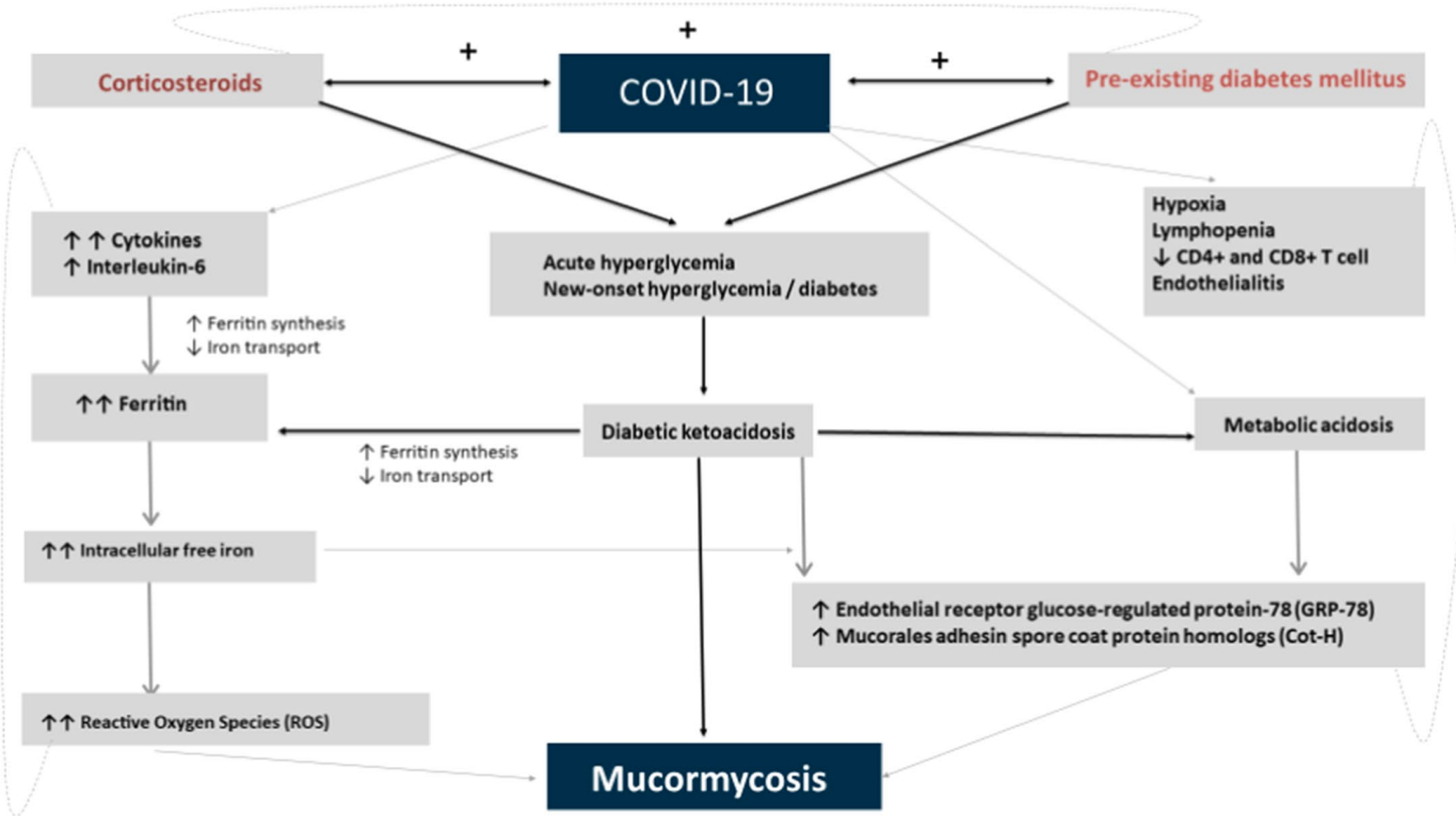

FIGURE 2 | Postulated interaction of diabetes, corticosteroid, and COVID-19 with mucormycosis.

along with mucormycosis at the time of hospitalization, and the other five patients who were given systemic steroid to manage COVID-19 developed mucormycosis (Sen et al., 2021).

In another study, 10 confirmed, clinically diagnosed orbital mucormycosis cases concurrently occurring with COVID-19 disease were reported (Sarkar et al., 2021). It is stated that the long-term use of steroids and monoclonal antibodies along with broad-spectrum antibiotics for the management of SARSCoV-2 increases the risk of developing mold-related infections. COVID-19 infection has a proclivity for causing severe pulmonary complications with subsequent alveolo-interstitial pathology. This whole cascade itself is responsible to predispose the SARS$\mathrm{CoV}-2$-infected patient toward the development of invasive fungal infections, especially in the sinuses and lungs (Gangneux 
et al., 2020). A recent study demonstrates that immune dysregulation exhibits a low population of $\mathrm{T}$ cells, CD4, and CD8 cells (Sen et al., 2021).

It is evident that mucormycosis is an extremely rare inhabitant in healthy individuals, but in immunocompromised conditions, the patient becomes predisposed to the infection as in mucormycosis. The several predisposing complications include DM, with or without DKA, malignancies, long-term neutropenia, organ transplantation, patients of immunosuppressive drugs or corticosteroid therapy, patients with high iron intake or hemochromatosis, severe burn injuries, deferoxamine therapies, immunodeficiency syndromes, malnutrition, and open wounds (Singh et al., 2021). In a recent study, it is quoted that a cumulative dose of prednisone $(>600 \mathrm{mg})$ or cumulative methylprednisone $(2-7 \mathrm{~g})$ given to the patient for a month before predisposes immunocompromised patients to develop mucormycosis (Singh et al., 2021). Another case reports patients receiving 5-14 days of steroid therapies, particularly people with DM developed mucormycosis infection (Singh et al., 2021).

Mucormycosis can be present in the nose, sinuses, lungs (pulmonary), orbit, CNS, skin, bones, kidney, joints, gastrointestinal tract, and mediastinum (invasive type). Studies show that giant cell invasion, eosinophilic necrosis, and thrombosis are the prime hallmarks of mucormycosis (Singh et al., 2021). These mucormycosis-related findings in the COVID-19 pandemic offer to exploit a new horizon of the research domain, especially when there are excessive corticosteroids used in the treatment and management of COVID-19-associated complications, especially in India.

\section{PATHOGENESIS OF MUCORMYCOSIS}

Mucormycosis is caused by the thermotolerant saprophytic fungi named Mucorales, an inhabitant of decaying organic matter and soil (Prakash et al., 2016, 2020). In an Indian study conducted on soil, several pathogenic species, such as Rhizopus, Lichtheimia, Cunninghamella, Rhizomucor, and Apophysomyces are reported (Prakash et al., 2016). In another hospital-based aeromycological study, pathogenic Mucorales is isolated from hospital air samples (Prakash et al., 2020). It is well documented that 11 genera and 27 species are known to cause mucormycosis (Prakash and Chakrabarti, 2019). In India, Rhizopus arrhizus is the most common cause of mucormycosis with some contribution from Rhizopusmicrospores and Rhizopushomothallicus (Prakash and Chakrabarti, 2021). ROCM is widely caused by the Rhizopus species and Apophysomyces variabilis because of their abundance in soil and air (Prakash and Chakrabarti, 2019). Some other Mucorales causative of mucormycosis in India are Rhizomucorpusillus, Cunninghamella species, Mucor species, Syncephalastrum species, and Saksenaea species (Frater et al., 2001; Prakash and Chakrabarti, 2021).

Patients lacking phagocytes or having impaired functional phagocytes are at more risk of developing mucormycosis (Sugar, 2005). In normal conditions, the host mononuclear and polymorphonuclear phagocytes inhibit the growth of Mucorales through the generation of oxidative metabolites, defensins, and cationic peptides (Ibrahim et al., 2012). In a previously published study, it is found that host neutrophils inhibit the growth of Rhizopus arrhizus as a result of which there is upregulation of toll-like receptors 2 (TLR-2) that induces the NF- $\kappa \beta$ pathwayrelated genes (Ibrahim et al., 2012). In the chronic hyperglycemic environment, especially in DM and also in the case of low $\mathrm{pH}$, especially DKA, the host's phagocytes become nonfunctional and thereby do not show a protective effect (Ibrahim et al., 2012). The precise mechanism or nonfunctionality of phagocytes in DM, ketoacidosis, and corticosteroid treatment is yet to be studied in detail.

Mucorales causing mucormycosis possess virulence features that cause the disease in the host. In addition, utilizing the host's iron is among the inhabitant traits of these Mucorales. Iron is a vital component of cell growth and development; thus, these Mucorales utilize it from the host's cells for their growth and multiplication. In a previously published report, a free form of iron is utilized by Mucorales, causing disease in the host, thereby suggesting that bound forms of iron in proteins, such as ferritin, transferrin, and lactoferrin, are untouched (Boelaert et al., 1993; Andrianaki et al., 2018). In patients with DKA, it can be easily explained that elevated levels of free iron in their serum facilitates the growth of Rhizopus arrhizus at acidic $\mathrm{pH}(7.3-6.88)$ but not at alkaline pH (7.78-8.38; Ibrahim et al., 2012). In another study, it is observed that patients on dialysis undergoing treatment with deferoxamine (iron-chelator) predispose them to lethal mucormycosis (Boelaert et al., 1991; Corzo-León et al., 2018).

\section{DIAGNOSIS OF MUCORMYCOSIS}

\section{Clinical Diagnosis}

Diagnosis of mucormycosis requires a high degree of suspicion, host factor identification, and swift assessment of clinical findings. Rhino-cerebral, pulmonary, and soft tissues are the common targets of Mucorales infection. In a pioneer study, a proposed algorithm was fabricated to diagnose rhino-cerebral mucormycosis in diabetic subjects (Corzo-León et al., 2018).

Mucormycosis can also be diagnosed by radiological intervention if the multiple nodules $(\geq 10)$ and pleural effusions are presentable. In computerized tomography (CT) scanning, a reverse halo sign (RHS) confirms the presence of mucormycosis (Legouge et al., 2014; Jung et al., 2015). In another study, positron emission tomography-computed tomography (PET/ $\mathrm{CT}$ ) using [18F]-fluorodeoxyglucose (FDG) was used to diagnose mucormycosis (Liu et al., 2013).

\section{Microscopic Examination and Culture-Based Diagnosis}

Mucormycosis diagnosis using microscopic examination and cultures are a conventional and keystone approach. The implication of direct microscopy using blankophor and calcufluor while in clinical specimens rapidly diagnose the presence of mucormycosis infection (Frater et al., 2001; Lass-Flörl et al., 2007; Lass-Flörl, 2009). Mucorales nonseptate or pauci-septate 
hyphae (having a width of $6-25 \mu \mathrm{m}$ ) shows irregular distribution with a ribbon-like feature and appearance in the microscopy. Microscopic diagnosis of fungal elements can be readily speculated using hematoxylin and eosin stains. In invasive mucormycosis, tissue histopathology exhibits infarcts and angioinvasion. In another antibody-based detection approach, mouse monoclonal anti-Rhizomucor antibody is used for immunohistochemical analysis to diagnose Mucorales and Entomophtorales (Lackner et al., 2014).

\section{Molecular-Based Diagnosis}

Molecular-based diagnosis of the mucormycosis is based on the conventional polymerase chain reaction (PCR), DNA sequencing, melt curve analysis of PCR products and restriction fragment length polymorphism analyses (RFLP; Hsiao et al., 2005; Larché et al., 2005; Nagao et al., 2005; Machouart et al., 2006; Kasai et al., 2008; Nyilasi et al., 2008; Springer et al., 2016). These techniques can either be used for the detection and identification of Mucorales; $18 \mathrm{~s}$ and 28S rRNA along with internal transcribed spacer (ITS) gene detection is the gold standard of all molecular assays in mucormycosis (Lackner et al., 2014). Studies in the past used formalin-fixed, paraffinembedded, or fresh tissue specimens for performing the molecular assays, yet their sensitivity and specificity is variable (Lackner et al., 2014). The matrix-assisted laser desorption ionizationtime of flight mass spectrometry (MALDI-TOF MS) approach is another pioneering technique for identifying Mucorales (Millon et al., 2019). Moreover, several molecular techniques, such as the FTR1 gene, cytochrome b, are used for the detection of Mucorales (Millon et al., 2019). Multiplex real-time quantitative PCR (mqPCR) using targets for the ITS1/ITS2 region of the gene with specific probes for R. oryzae, R. microsporus, and Mucor spp. using specific customized primers are able to detect the Mucorales species (Millon et al., 2019).

\section{MANAGEMENT OF MUCORMYCOSIS}

The efficient management of mucormycosis depends on mainly early diagnosis, limiting the predisposing risk factors, surgical debridement (if applicable), and implication of antifungal agents. In early management of mucormycosis, polyene therapy within 5 days of early diagnosis shows significant improvement in survival compared with the therapy of polyene administered after 6 days of the diagnosis ( $83 \%$ vs. $49 \%$ survival; Chamilos et al., 2005). Early diagnosis is credited with the invention of new molecular biology assays, including real-time quantitative PCR, that help extensively in the timely diagnosis and management of mucormycosis. In a previously published study, mqRTPCR was used against the target for the 28SrRNA gene for the diagnosis of mucormycosis by identification of Rhizopus, Mucor, and Cunninghamella species at the same time in a single specimen (Kasai et al., 2008). In mucormycosis-associated ROCS, CT scans exclusively present the sinusitis, ignoring the deeper infection that is also probably suggestive of mucormycosis. To overcome this issue, magnetic resonance imagining (MRI) seems to be more sensitive than CT scans as it diagnoses the orbital and CNS involvement.

In another approach for management of mucormycosis, limiting or reversal of the causes for predisposition must be the point of focus in such patients. Moreover, it is cumbersome to reverse or limit the underlying causes in such diseased patients when managing for mucormycosis infection. It is suggested to use low-dose administration for corticosteroid (immunosuppressive medication) if possible in such patients. Such an approach also includes aggressive glycemic control and normalization of the acid-base environment to prevent DKA.

Surgical management in mucormycosis involves debridement of the necrotic tissues for complete elimination of mucormycosis. This approach is the last option to treat such infected patients when there is no or limited penetration of antifungal agents/ drugs at the site of infection due to tissue necrosis and blood vessel thrombosis. In a previously published study, surgical debridement of the tissue was found to be on top when tested in a logistic regression model in patients with mucormycosis with promising outcomes (Roden et al., 2005). In another study, patients who did not undergo surgical debridement showed significantly higher mortality compared with those who underwent surgical debridement of the tissue in mucormycosis disease (Asai et al., 2003).

Primary antifungal therapy includes the use of amphotericin B, liposomal amphotericin B, and amphotericin B lipid complex. The dose of these antifungal agents in the treatment of mucormycosis is still not known or fixed under treatment guidelines. However, starting dosages of $1 \mathrm{mg} / \mathrm{kg} /$ day of amphotericin B and $5-7.5 \mathrm{mg} / \mathrm{kg} /$ day for liposomal amphotericin $\mathrm{B}$ and amphotericin B lipid complex are commonly prescribed in clinical practices in both children and adults. A previously conducted study proved that a higher dose of liposomal amphotericin B ( $>10 \mathrm{mg} / \mathrm{kg} /$ day) does not show any significant pharmacokinetic advantage in patients with mucormycosis (Walsh et al., 2001).

Salvage therapy provides an additional advantage in the management of mucormycosis. Deferasirox or posaconazole are some of the offered choices for patients with mucormycosis and those who are intolerant to polyene therapy. Sufficient data for posaconazole is available from clinical trials regarding the efficacy and safety of this drug in the management of mucormycosis. However, if deferasirox must be added, it should be given only for 2-4 weeks during the salvage therapy as, beyond 4 weeks, it causes toxicity (Nick et al., 2002). For patients with mucormycosis who are undergoing immunosuppressive medications, the secondary antifungal agents should be continued simultaneously. Posaconazole can be the second immediate choice of treatment if polyenes cannot be administered in such patients for a prolonged period.

In the treatment of mucormycosis, antifungal drugs are the first-line treatment options, especially in prophylaxis and invasive fungal infections. These azoles have associated long-term side effects, especially in patients with hematologic malignancies. The long-term complications or side effects associated with the azole implication include hormone-related impairments, such as alopecia, impotence, oligospermia, decreased libido, 
gynecomastia, hyponatremia, hypokalemia, and rarely adrenal insufficiency, along with hepatotoxicity (Benitez and Carver, 2019). In another study, it is found that voriconazole and posaconazole are causative factors for peripheral neuropathies and pancreatitis if used in combination with itraconazole (Benitez and Carver, 2019). It is also observed that voriconazole is associated with the development of complications such as periostitis, squamous cell carcinoma, and phototoxic reactions (Benitez and Carver, 2019). Because these azole therapies cause several long-term complications if used for a long time period, to overcome these associated limitations with azoles and associated complications, MSC-based therapeutic approaches could prove to be helpful, safer, and efficient without any conflict with patient's health.

\section{MSC-BASED MANAGEMENT OF COVID-19-ASSOCIATED MUCORMYCOSIS}

Multipotent stem cells exhibit immunomodulation characteristics that were found to be safe for the treatment of COVID-19 (Akbari and Rezaie, 2020; Kumar, 2020; Wu et al., 2020). The FDA has already given its consent for using MSC-based therapy to treat COVID-19 and its associated complications. Regenerative medicine has again proven effective and efficient in curing this worldwide pandemic of COVID-19 and its associated comorbidities without any conflict. In a previously published study, IL-17, produced by MSCs, activates the NFKB pathway to downregulate TGF- $\beta$ production in MSCs, resulting in abolishment of MSC-based immunomodulation (Yang et al., 2013). Moreover, these IL-17+ MSCs possess anti-Candida albicans growth effects in vitro and therapeutic effect in C. albicans-infected mice.

Mucormycosis is a life-threatening opportunistic infection that severely affects immunocompromised patients, especially SARS-CoV-2-infected patients. In a recently published case report, it is found that a patient with acute myeloid leukemia (AML) presented with pulmonary mucormycosis and was treated with the antifungal agent voriconazole preceded by a 1 month transplant with peripheral blood stem cells followed by isavuconazole, and the patient showed a significant reduction in ground glass opacities in the CT scan (Aqsa and Chow, 2019). This study is suggestive of using antifungal agents in combination with stem cell transplantation for obtaining a better outcome. MSCs have a tendency to reduce inflammation, repair tissue, and do pathogenic clearance (Hashmi et al., 2016).

COVID-19 and its associated mucormycosis impair the immune system by initiating the cytokine storm in such patients. MSC-based therapy is coming up with new hope for promoting endogenous repair and inhibiting the cytokine storm, hence, helpful in managing COVID-19 and its associated mucormycosis (Rahimkhoei et al., 2021). In a previously conducted study on COVID-19 patients, injection of MSCs to lungs in pulmonary disease showed a protective effect on the endothelial cells (Liang et al., 2020). In another study published recently, it is quoted that MSC transplantation significantly reduced neutrophil-mediated inflammation of the airways by inhibiting the Th17 signaling pathway in a mouse model of asthma triggered by the fungus Aspergillus fumigatus hyphal extract (Arango et al., 2018). Bone marrow-derived MSCs show an immunomodulatory effect on macrophages stimulated by Aspergillus fumigatus conidia that further lowers the expression of tumor necrosis factor- $\alpha$ (TNF- $\alpha$ ) and increases the expression of IL-10 (Arango et al., 2018).

\section{HOST IMMUNE DYSREGULATION IN MUCORMYCOSIS}

Bronchial alveolar macrophages (BAM) contribute as vital components of the innate immune system, assuming the first line of defense (Aberdein et al., 2013). In a murine study, it is found that BAM is unable to inhibit the growth of $R$. oryzae in an immunosuppressive environment (Waldorf et al., 1984). In another study, Rhizopus spp. exhibit inhibition of phagosome maturation in the presence of melanin on their spores and mediate iron metabolism that helps in regulation of immune defense (Ghuman and Voelz, 2017). Mucorales recognize the epithelial cells when they come in contact for causing infection. Epithelial cells are the first line of defense present in the outer surface of the skin and alveoli that protects against fungal pathogens (Ghuman and Voelz, 2017).

In a previously published molecular study, human epithelial cells (A-549) were observed to interact with L. corymbifera, $R$. oryzae, $R$. delemar, and $C$. bertholletiae mediated through platelet-derived growth factor receptor B (PDGFRB) signaling in the infection phase (Chibucos et al., 2017). Moreover, another transcriptome analysis on epithelial cells encountered with $R$. arrhizus var. delemar shows increased expression of epidermal growth factor receptor (EGFR) in lungs (Watkins et al., 2018). Polymorphonuclear leukocytes (PMNs) or neutrophil granulocytes play a vital role in inhibiting pathogen growth by initiating chemotactic factors such as cytokines. During mucormycosis, these chemotactic factors modulate the immune response in the infected host (Chinn and Diamond, 1982).

In a published study, it is found that there is increased generation of superoxide anion $\left(\mathrm{O} 2^{-}\right)$when encountered with the hyphae of mucoralean species that, in turn, modulate the neutrophils (Chamilos et al., 2008b). In mucormycosis, the hyphae of Rhizopus spp. contribute to the activation of TLR-2, IL-1B, and TNF- $\alpha$ of neutrophils (Chamilos et al., 2008a). In another study, if TLRs in combination with liposomal amphotericin B is given to a Mucorales-infected host, neutrophils reduce the proinflammatory responses by switching TLR-2 to TLR-4, in turn, providing protection against Mucorales infection without any cytotoxicity (Bellocchio et al., 2005).

$\mathrm{T}$ cells are the adaptive immune system component that initiates the production of interleukins such as IL-4, 10, and 17 , along with IFN- $\gamma$. The Mucorales hyphal encounter triggers the immune regulation of these interleukins by generating Mucorales-specific $\mathrm{T}$ cells through stimulation of CD4+ T cells (Castillo et al., 2018). Another category of cells named NK 
cells is involved in pathogen clearance by reducing dissemination (Vivier et al., 2008). In a study, it is found that Mucorales hyphae are destroyed by stimulated and unstimulated NK cells except resting (dormant) spores mediated by perforin protein secreted by the NK cells (Schmidt et al., 2016). Similarly, platelets and endothelial cells play an important role in the recognition and killing of Mucorales hyphae and phagocytosis of the fungal spores (mediated by glucose-regulated protein 78), respectively (Liu et al., 2010; Jenne and Kubes, 2015). Mucorales interaction with the host immune system is modulated by several factors, including hyperglycemia and DKA. Deferoxamine- and DKA-treated patients are shown to be predisposed to mucormycosis. Diabetic subjects show uncontrolled hyperglycemia, increased ketone bodies [e.g., $\beta$-hydroxy butyrate (BHB)] and low $\mathrm{pH}$ due to accumulation of these ketone bodies in the blood that impairs the transferrin protein binding characteristic to chelate iron (Figure 3). These factors, including high blood glucose, excessive iron, and the presence of BHB promote the growth of fungus mediated by suppression of T-lymphocyte induction as shown in Figure 3.

\section{IMMUNOMODULATORY PROTECTIVE MECHANISM OF MSCS PROSPECTIVELY IN MUCORMYCOSIS}

The mechanism by which MSCs exert immunomodulation in host cells is mediated by inhibition of CD4+ and CD8+ T cells, $B$ lymphocytes, and NK cells. Human bone marrow-derived stem cells (hBMSCs) exhibit CD73+, CD90+, and CD105+ along with CD45-, CD34-, CD14-, CD11b-, CD79a-, and HLA class II (Dominici et al., 2006; Ma et al., 2014; Figure 4). Studies show that hBMSCs produce several immunomodulatory factors, including chemokines, cytokines, growth factors, and proteins of extracellular matrix that play a significant role in building immunity of the host and reducing the inflammatory response along with tissue regeneration (Burrello et al., 2016). hBMSCs recognize the invading pathogen by TLR present on the cell surface and express antimicrobial peptides; in case of antigenic presentation, these cells may behave as pro-inflammatory and immunosuppressive cells (Auletta et al., 2012).

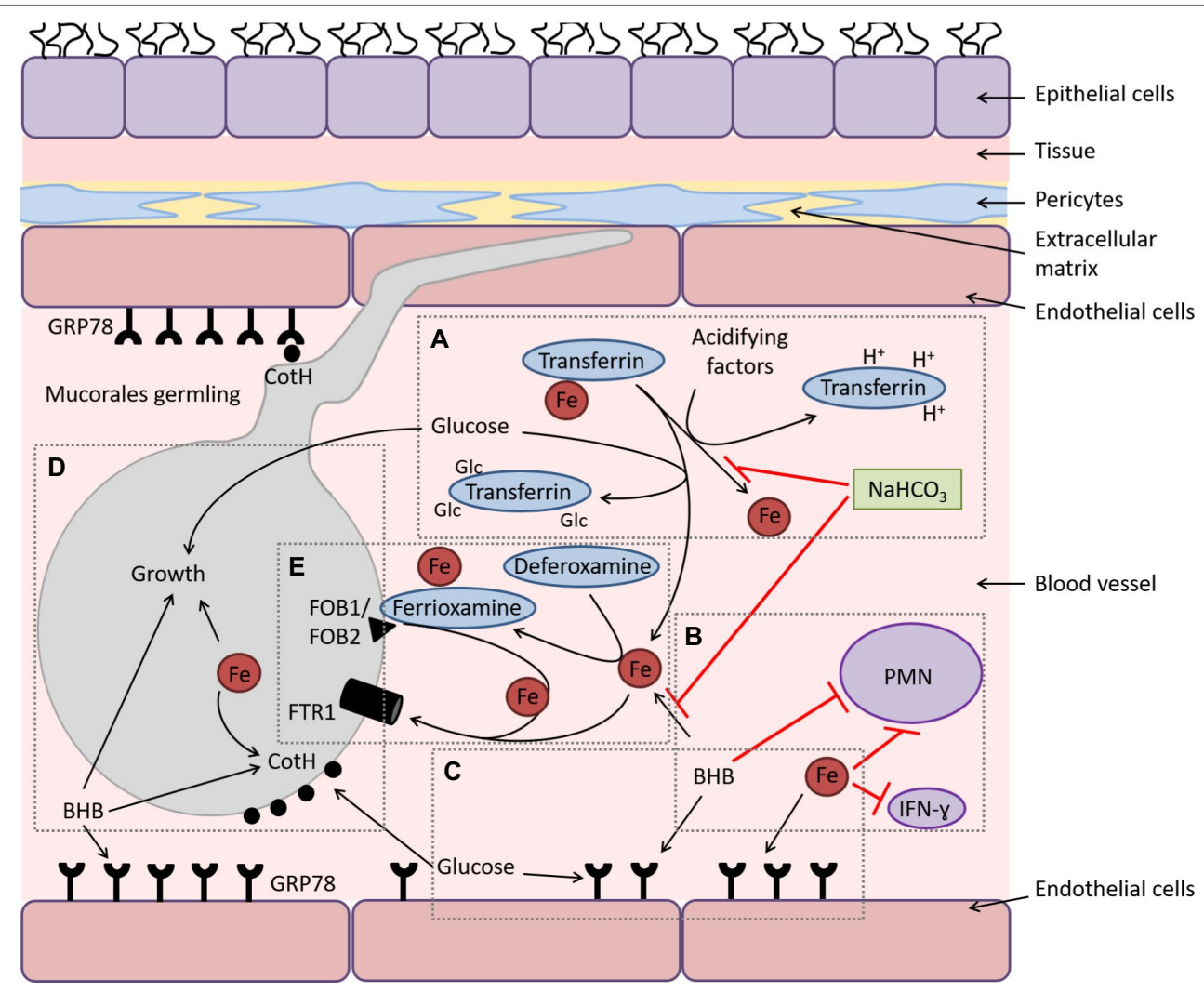

FIGURE 3 | Mucorales interaction with endothelial cells during hematogenous dissemination/organ seeding and the effect of host factors on these interactions and on the immune response. (A) Hyperglycemia and ketoacidosis result in liberation of iron from serum-sequestering proteins (e.g., transferrin) via glycosylation and protonation, respectively. (B) Ketone bodies (e.g., $\mathrm{BHB}$ ) and free iron negatively affect the immune response to the infection, and sodium bicarbonate $\left(\mathrm{NaHCO}_{3}\right)$ reverses this negative effect by preventing iron release from transferrin and neutralizing acidity. (C) Surface expression of glucose-regulator protein 78 (GRP78) on endothelial cells is enhanced to cope with the stress elicited by hyperglycemia, free iron, and ketone bodies. (D) Glucose, free iron (transported by the high-affinity iron permease [Ftr1p]), and BHB also enhance the expression of the fungal cell surface $\mathrm{CotH}$, which results in invasion of the endothelium and augmentation of fungal growth. (E) In deferoxamine-treated hosts, the iron-rich ferrioxamine binds to its fungal receptor (ferrioxamine binding proteins [Fob1/Fob2]) then releases iron via a reductive step prior to feeding invading Mucorales via Ftr1p transportation. (Adapted from Ref (Baldin and lbrahim, 2017) under the terms of the Creative Commons Attribution License 4.0). 


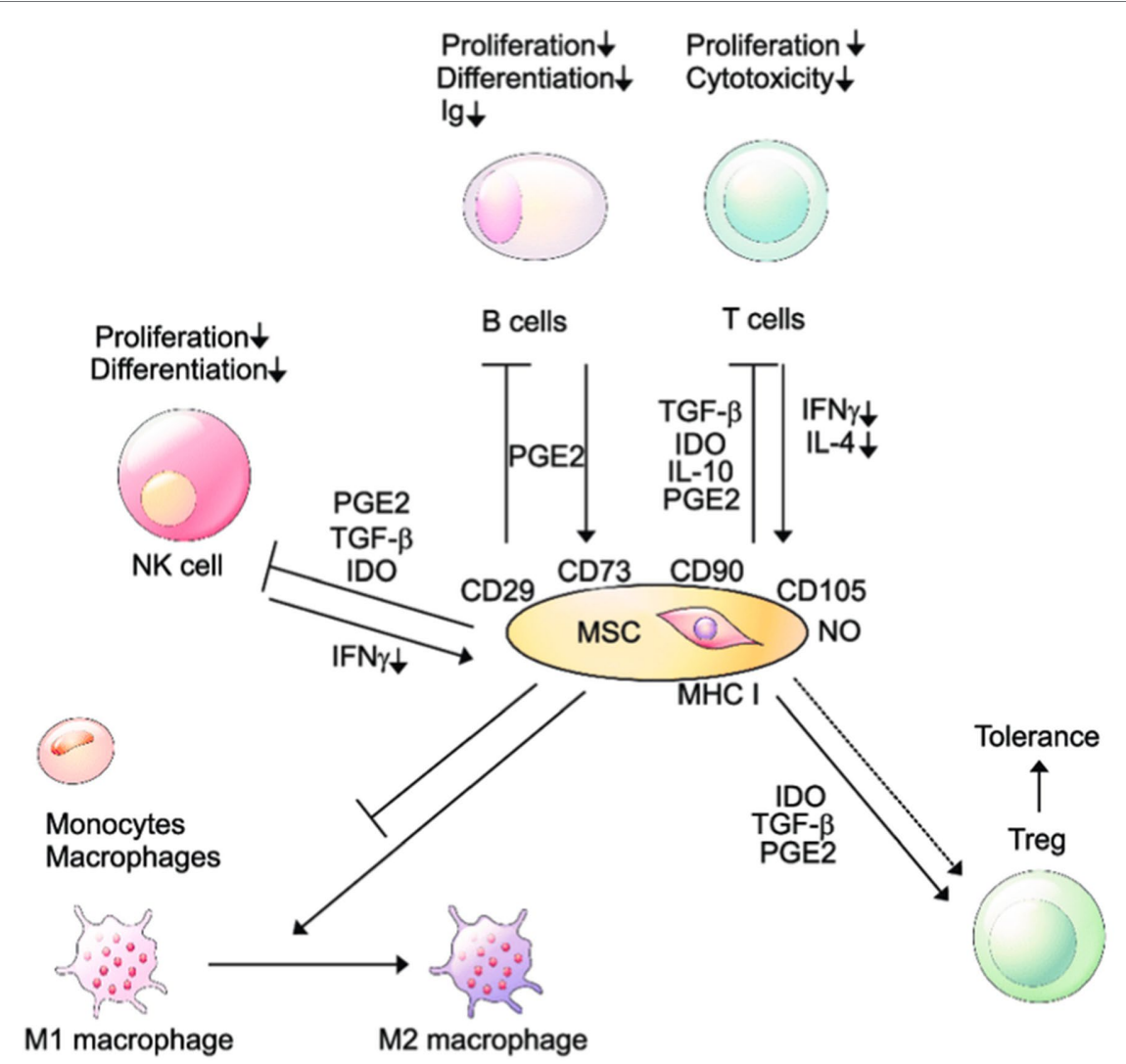

FIGURE 4 | Immunomodulation by MSCs. Ig, immunoglobulin; NK, natural killer; PGE, prostaglandin E; TGF, transforming growth factor; IDO, indoleamine 2,3-dioxygenase; IFN, interferon; IL, interleukin; MHC, major histocompatibility complex, NO, nitric oxide. (Adapted from Ref (Kang et al., 2020) under the terms of the Creative Commons Attribution License 4.0).

In recent research conducted on a murine model of chronic pulmonary paracoccidioidomycosis, BMSCs show a promising approach in improving health outcomes and boosting immune responses mediated by depletion of the neutrophils (Puerta-Arias et al., 2016). In vitro and in vivo study demonstrates that IL-17+ MSCs inhibit the growth of Candida albicans. MSCs are proven to show a protective effect in asthma induced by Aspergillus fumigatus hyphal extract mediated by inhibition of Th17 signaling mechanism (Yang et al., 2013). Similarly, BMSCs induce an immunomodulatory effect on A. fumigatus conidia-stimulated macrophages through step-down of TNF- $\alpha$ secretion and step-up of IL-10 production (Lathrop et al., 2014).

Mucorales triggers the immune response postrecognition by the endothelial cells on an antagonistic counterpart, and MSCs modulate and reverse these immune responses and protect the host from infection such as in mucormycosis by inducing naïve and effector T cells, suppression of NK cells, increased IL-17 secretion, neutropenia, and inhibiting the cytokine storm at the site of fungal infection. MSCs, apart from inducing immunomodulatory characteristics, regenerate the infected skin/tissue, which an antifungal drug is unable to do. In a previously published study, the antifungal host response effect of human MSCs (hMSCs) was investigated on
anti-Aspergillus CD4+ $\mathrm{T}$ cells, and it was found that antiAspergillus $\mathrm{T}$ cells initiate the IL- 6 production of hMSCs (Schmidt et al., 2017).

MSCs modulate the immune molecules of the immune system and are proven to be beneficial in the survival of patients suffering from immune-related complications. MSCs are known to prevent the overstimulation of the immune system as they contribute to the suppression of the immune functions mediated by stimulation of pro-inflammatory factors (IFN- $\gamma$, TNF- $\alpha$, and IL- $1 \beta$; Jiang and $\mathrm{Xu}, 2020$; Table 1). Among these immune modulators, IFN- $\gamma$ plays a crucial role in controlling the suppressive function of MSCs as it stimulates the expression of programmed cell death ligands 1 and 2 (PD-L1/L2) along with downregulation of immunoglobulinlike transcript receptors (ILTRs; Jiang and Xu, 2020). It is supported by other literature, in which the authors give Nivolumab along with IFN- $\gamma$ and find promising results in the treatment of intractable mucormycosis (Grimaldi et al., 2017). Furthermore, immunosuppressive characteristics of MSCs also contribute in downregulating the expression of MHC-I, MHC-II, and FasL along with CD80, CD86, CD40, and CD40L factors (Jiang and Xu, 2020). The in-built property of the MSCs to express chemokines along with several adhesion proteins help in the recruitment of immune cells such as C-X-C motif chemokine receptor 3 (CXCR3), C-C motif chemokine receptor 5 (CCR5), vascular cell adhesion molecule 
TABLE 1 | Immunological modulation of MSCS.

\begin{tabular}{|c|c|c|c|}
\hline $\begin{array}{l}\text { Immunomodulatory } \\
\text { factors }\end{array}$ & Species & Roles in MSC-mediated immunosuppression & References \\
\hline iNOS & Murine MSCs & Inhibits T-cell proliferation & Ren et al., 2008 \\
\hline CCL2 & Murine MSCs & Inhibits CD4+ Th17 cells & Rafei et al., 2009 \\
\hline IDO & Human MSCs & Inhibits T-cell proliferation & Ren et al., 2009 \\
\hline Semaphorin-3A & Human MSCs & Inhibits T-cell proliferation & Lepelletier et al., 2010 \\
\hline $\mathrm{B} 7-\mathrm{H} 4$ & Human MSCs & Inhibits T-cell activation and proliferation & Xue et al., 2010 \\
\hline HLA-G & Human MSCs & Inhibits PBMC response & Rizzo et al., 2008 \\
\hline Galectin(s) & Human MSCs & Inhibits T-cell proliferation & Lepelletier et al., 2010 \\
\hline $\mathrm{HO}-1$ & Murine MSCs & Inhibits T-cell response & Chabannes et al., 2007 \\
\hline IL-6 & Murine MSCs, human MSCs & Inhibit the differentiation of dendritic cells; inhibit T-cell proliferation & Djouad et al., 2007; Najar et al., 2009 \\
\hline TGF- $\beta$ & human MSCs & inhibits NK cell activation and function & Sotiropoulou et al., 2006 \\
\hline $\mathrm{IL}-10$ & Murine MSCs, human MSCs & Inhibits T-cell responses, decreases Th17 cell differentiation & $\begin{array}{l}\text { Rasmusson et al., 2005; Qu et al., } \\
2012\end{array}$ \\
\hline PGE2 & Murine MSCs, & Induces Foxp3+ Tregs & English et al., 2009 \\
\hline FasL & human MSCs & Induces T-cell apoptosis & Akiyama et al., 2012 \\
\hline
\end{tabular}

CCL2, chemokine ligand 2; DC, dendritic cells; FasL, Fas ligand; HLA-G, human leukocyte antigen G; HO-1, heme oxygenase-1; IDO, indoleamine 2,3-dioxygenase; iNOS, inducible nitric oxide synthase; LIF, leukemia inhibitory factor; MSCs, mesenchymal stem cells; PGE2, prostaglandin E2; PD-L1/2, programmed cell death 1 ligand1/2; PBMC, peripheral blood mononuclear cells; TSG6, TNF- $\alpha$ stimulated gene/protein 6. [Adapted from Ref (Rafei et al., 2009) under the terms of the Creative Commons Attribution License 4.0].

1 (VCAM-1), and intercellular adhesion molecule 1 (ICAM-1) ligands that also help in the suppression of inflammatory mechanisms (Jiang and Xu, 2020). Recently, published studies demonstrate the role of small molecules, including monoclonal antibodies, vaccines, peptides, and interferon in the treatment of the SARS-CoV-2 that might be explored further in treatment of SARS-CoV-2associated mucormycosis.

\section{CONCLUSION}

Invasive mold infections vary from patient to patient depending upon the immunocompromised ability of the immune system in the infected host. Recently, mucormycosis is showing an increasing trend due to several reasons associated with COVID-19, including comorbidities such as DM, DKA, prolonged steroid treatment, that hamper SARS-CoV-2infected host immunity and provide an opportunity for Mucorales to inhabit the host. Early diagnosis of these species should be a matter of concern by using molecular biological assessment tools along with the clinical diagnosis. Because antifungal drugs (itraconazole, posaconazole, or voriconazole) having the azole functional group is the first choice in mucormycosis possess some limitation of having side effects on long-term use, MSCs can be an alternative cell-based treatment approach that can be used without conflict. MSCs exhibit an immunomodulatory role in the host and protect it from fungal infection by boosting the immune system through the release of various chemotactic proteins.

Moreover, very limited studies are present explaining the mechanism of immunomodulation adopted by MSCs in

\section{REFERENCES}

Aberdein, J. D., Cole, J., Bewley, M. A., Marriott, H. M., and Dockrell, D. H. (2013). Alveolar macrophages in pulmonary host defence-the unrecognized mucormycosis. However, assumptions can be made for using MSCs as prospective therapy in the treatment of mucormycosis. No conclusive data of clinical trials are available to include MSCs in treatment of mucormycosis.

\section{AUTHOR'S NOTE}

Currently involved in COVID-19 testing duties; Prashant Tripathi: Nodal Officer, COVID-19 Testing Laboratory, GSVM Medical College, Kanpur; Richa Giri: Nodal Officer, Multidisciplinary Research Unit, GSVM Medical College, Kanpur.

\section{AUTHOR CONTRIBUTIONS}

AR, SA, and G-BJ: conceptualization. AR, SA, G-BJ, KG, SB, QM, SR, and RT: formal analysis. KG, SB, SR, and RT: investigation. AR, SA, and G-BJ: methodology. PT, RG, SA, MS, and HK: supervision. PT, RG, SA, MS, and HK: visualization. AR, SA, G-BJ, and QM: writing - original draft. PT, RG, SA, MS, and HK: writing - review and editing. All authors have read and approved the manuscript and ensure that this is the case.

\section{ACKNOWLEDGMENTS}

$\mathrm{AR}$ and KG are thankful to Department of Health Research, Ministry of Health and Family Welfare for providing financial assistance in the form of salary. The authors are thankful to Principal, GSVM Medical College Kanpur for providing facility to perform the present study and motivated us for continuous research. 
Akiyama, K., Chen, C., Wang, D., Xu, X., Qu, C., Yamaza, T., et al. (2012). Mesenchymal-stem-cell-induced immunoregulation involves FAS-ligand-/ FAS-mediated T cell apoptosis. Cell Stem Cell 10, 544-555. doi: 10.1016/j. stem.2012.03.007

Andrianaki, A. M., Kyrmizi, I., Thanopoulou, K., Baldin, C., Drakos, E., Soliman, S. S., et al. (2018). Iron restriction inside macrophages regulates pulmonary host defense against Rhizopus species. Nat. Commun. 9:3333. doi: 10.1038/s41467-018-05820-2

Aqsa, A., and Chow, M.-Y. (2019). Pulmonary mucormycosis treated with combination antifungals and lobectomy prior to stem cell transplant in a patient with AML. Chest 156:A629. doi: 10.1016/j.chest.2019.08.615

Arango, J. C., Puerta-Arias, J. D., Pino-Tamayo, P. A., Arboleda-Toro, D., and González, Á. (2018). Bone marrow-derived mesenchymal stem cells transplantation alters the course of experimental paracoccidioidomycosis by exacerbating the chronic pulmonary inflammatory response. Med. Mycol. 56, 884-895. doi: 10.1093/mmy/myx 128

Asai, K., Suzuki, K., Takahashi, T., Ito, Y., Kazui, T., and Kita, Y. (2003). Pulmonary resection with chest wall removal and reconstruction for invasive pulmonary mucormycosis during antileukemia chemotherapy. Jpn. J. Thorac. Cardiovasc. Surg. 51, 163-166. doi: 10.1007/s11748-003-0055-y

Auletta, J. J., Deans, R. J., and Bartholomew, A. M. (2012). Emerging roles for multipotent, bone marrow-derived stromal cells in host defense. Blood 119, 1801-1809. doi: 10.1182/blood-2011-10-384354

Baldin, C., and Ibrahim, A. S. (2017). Molecular mechanisms of mucormycosisThe bitter and the sweet. PLoSPathog 13:e1006408. doi: 10.1371/journal. ppat.1006408

Bellocchio, S., Gaziano, R., Bozza, S., Rossi, G., Montagnoli, C., Perruccio, K., et al. (2005). Liposomal amphotericin B activates antifungal resistance with reduced toxicity by diverting toll-like receptor signalling from TLR-2 to TLR-4. J. Antimicrob. Chemother. 55, 214-222. doi: 10.1093/jac/dkh542

Benitez, L. L., and Carver, P. L. (2019). Adverse effects associated with longterm Administration of Azole Antifungal Agents. Drugs 79, 833-853. doi: 10.1007/s40265-019-01127-8

Bernardo, M. E., and Fibbe, W. E. (2013). Mesenchymal stromal cells: sensors and switchers of inflammation. Cell Stem Cell 13, 392-402. doi: 10.1016/j. stem.2013.09.006

Boelaert, J. R., de Locht, M., Van Cutsem, J., Kerrels, V., Cantinieaux, B., Verdonck, A., et al. (1993). Mucormycosis during deferoxamine therapy is a siderophore-mediated infection: in vitro and in vivo animal studies. J. Clin. Invest. 91, 1979-1986. doi: 10.1172/JCI116419

Boelaert, J. R., Fenves, A. Z., and Coburn, J. W. (1991). Deferoxamine therapy and mucormycosis in dialysis patients: report of an international registry. Am. J. Kidney Dis. 18, 660-667. doi: 10.1016/S0272-6386(12)80606-8

Burrello, J., Monticone, S., Gai, C., Gomez, Y., Kholia, S., and Camussi, G. (2016). Stem cell-derived extracellular vesicles and immune-modulation. Front. Cell Dev. Biol. 4:83. doi: 10.3389/fcell.2016.00083

Caccamo, N., La Mendola, C., Orlando, V., Meraviglia, S., Todaro, M., Stassi, G., et al. (2011). Differentiation, phenotype, and function of interleukin-17-producing human V $\gamma 9$ V82 T cells. Blood 118, 129-138. doi: 10.1182/blood-2011-01-331298

Castillo, P., Wright, K. E., Kontoyiannis, D. P., Walsh, T., Patel, S., Chorvinsky, E., et al. (2018). A new method for reactivating and expanding $\mathrm{T}$ cells specific for Rhizopus oryzae. Molecular Therapy-Methods \& Clinical Development 15, 305-312. doi: 10.1016/j.omtm.2018.03.003

Chabannes, D., Hill, M., Merieau, E., Rossignol, J., Brion, R., Soulillou, J. P., et al. (2007). A role for heme oxygenase- 1 in the immunosuppressive effect of adult rat and human mesenchymal stem cells. Blood 110, 3691-3694. doi: 10.1182/blood-2007-02-075481

Chamilos, G., Lewis, R. E., and Kontoyiannis, D. P. (2008a). Delaying amphotericin B-based frontline therapy significantly increases mortality among patients with hematologic malignancy who have zygomycosis. Clinical Infect. Dis. 47, 503-509. doi: 10.1086/590004

Chamilos, G., Lewis, R. E., Lamaris, G., Walsh, T. J., and Kontoyiannis, D. P. (2008b). Zygomycetes hyphae trigger an early, robust proinflammatory response in human polymorphonuclear neutrophils through toll-like receptor 2 induction but display relative resistance to oxidative damage. Antimicrob. Agents Chemother. 52:722. doi: 10.1128/AAC.01136-07

Chamilos, G., Marom, E. M., Lewis, R. E., Lionakis, M. S., and Kontoyiannis, D. P. (2005). Predictors of pulmonary zygomycosis versus invasive pulmonary aspergillosis in patients with cancer. Clin. Infect. Dis. 41, 60-66. doi: 10.1086/430710
Chibucos, M. C., Soliman, S., Gebremariam, T., Lee, H., Daugherty, S., Orvis, J., et al. (2017). An integrated genomic and transcriptomic survey of mucormycosiscausing fungi. Nat. Commun. 7:12218. doi: 10.1038/ncomms12218

Chinn, R. Y., and Diamond, R. D. (1982). Generation of chemotactic factors by Rhizopus oryzae in the presence and absence of serum: relationship to hyphal damage mediated by human neutrophils and effects of hyperglycemia and ketoacidosis. Infect. Immun. 38:1123. doi: 10.1128/iai.38.3.1123-1129.1982

Chowdhary, A., Tarai, B., Singh, A., and Sharma, A. (2020). Multidrug-resistant Candida auris infections in critically ill coronavirus disease patients, India, April-July 2020. Emerg. Infect. Dis. 26, 2694-2696. doi: 10.3201/eid2611.203504

Corzo-León, D. E., Chora-Hernández, L. D., Rodríguez-Zulueta, A. P., and Walsh, T. J. (2018). Diabetes mellitus as the major risk factor for mucormycosis in Mexico: epidemiology, diagnosis, and outcomes of reported cases. Med. Mycol. 56, 29-43. doi: 10.1093/mmy/myx017

Djouad, F., Charbonnier, L. M., Bouffi, C., Louis-Plence, P., Bony, C., Apparailly, F., et al. (2007). Mesenchymal stem cells inhibit the differentiation of dendritic cells through an interleukin-6-dependent mechanism. Stem Cells 25, 2025-2032. doi: 10.1634/stemcells.2006-0548

Dominici, M. L., Le Blanc, K., Mueller, I., Slaper-Cortenbach, I., Marini, F. C., Krause, D. S., et al. (2006). Minimal criteria for defining multipotent mesenchymal stromal cells. The International Society for Cellular Therapy position statement. Cytotherapy 8, 315-317. doi: 10.1080/14653240600855905

Dominici, M., Le Blanc, K., Mueller, I., Slaper-Cortenbach, I., Marini, F., Krause, D., et al. (2006). Minimal criteria for defining multipotent mesenchymal stromal cells. The International Society for Cellular Therapy position statement. Cytotherapy 8, 315-317. doi: 10.1080/14653240600855905

English, K., Ryan, J. M., Tobin, L., Murphy, M. J., Barry, F. P., and Mahon, B. P. (2009). Cell contact, prostaglandin E2 and transforming growth factor beta 1 play non-redundant roles in human mesenchymal stem cell induction of CD4+ CD25Highforkhead box P 3+ regulatory T cells. Clin. Exp. Immunol. 156, 149-160. doi: 10.1111/j.1365-2249.2009.03874.x

Farnoosh, G., Alishiri, G., Hosseini Zijoud, S. R., Dorostkar, R., and Jalali, F. A. (2020). Understanding the severe acute respiratory syndrome coronavirus 2 (SARS-CoV-2) and coronavirus disease (COVID-19) based on available evidence-A narrative. J Mil Med 22, 1-11. doi: 10.1159/000512141

Frater, J. L., Hall, G. S., and Procop, G. W. (2001). Histologic features of zygomycosis: emphasis on perineuralinvasion and fungal morphology. Arch. Pathol. Lab. Med. 125, 375-378. doi: 10.5858/2001-125-0375-HFOZ

Gangneux, J. P., Bougnoux, M. E., Dannaoui, E., Cornet, M., and Zahar, J. R. (2020). Invasive fungal diseases during COVID-19: we should be prepared? J Mycol Med 30:100971. doi: 10.1016/j.mycmed.2020.100971

Ghuman, H., and Voelz, K. (2017). Innate and adaptive immunity to Mucorales. Journal of Fungi. 3:48. doi: 10.3390/jof3030048

Grimaldi, D., Pradier, O., Hotchkiss, R. S., and Vincent, J. L. (2017). Nivolumab plus interferon- $\gamma$ in the treatment of intractable mucormycosis. Lancet Infect. Dis. 17:18. doi: 10.1016/S1473-3099(16)30541-2

Hashemian, S. M. R., Aliannejad, R., Zarrabi, M., Soleimani, M., Vosough, M., Hosseini, S. E., et al. (2021). Mesenchymal stem cells derived from perinatal tissues for treatment of critically ill COVID-19-induced ARDS patients: a case series. Stem Cell Res Ther 12:91. doi: 10.1186/s13287-021-02165-4

Hashmi, S., Ahmed, M., Murad, M. H., Litzow, M. R., Adams, R. H., Ball, L. M., et al. (2016). Survival after mesenchymal stromal cell therapy in steroidrefractory acute graft-versus-host disease: systematic review and meta-analysis. Lancet Haematol 3, e45-e52. doi: 10.1016/S2352-3026(15)00224-0

Hsiao, C. R., Huang, L., Bouchara, J. P., Barton, R., Li, H. C., and Chang, T. C. (2005). Identification of medically important molds by an oligonucleotide array. J. Clin. Microbiol. 43:3760. doi: 10.1128/JCM.43.8.3760-3768.2005

Ibrahim, A., and Kontoyiannis, D. (2013). Update on mucormycosis pathogenesis. Curr. Opin. Infect. Dis. 26, 508-515. doi: 10.1097/QCO.0000000000000008

Ibrahim, A. S., Spellberg, B., Walsh, T. J., and Kontoyiannis, D. P. (2012). Pathogenesis of mucormycosis. Clin. Infect. Dis. 54(suppl. 1), S16-S22. doi: 10.1093/cid/cir865

Jenne, C. N., and Kubes, P. (2015). Platelets in inflammation and infection. Platelets 26, 286-292. doi: 10.3109/09537104.2015.1010441

Jiang, W., and $\mathrm{Xu}, \mathrm{J}$. (2020). Immune modulation by mesenchymal stem cells. Cell Prolif. 53:e12712. doi: 10.1111/cpr.12712

Johnson, A. K., Ghazarian, Z., Cendrowski, K. D., and Persichino, J. G. (2021). Pulmonary aspergillosis and mucormycosis in a patient with COVID-19. Med. Myco. Case Rep. 32, 64-67. doi: 10.1016/j.mmcr.2021.03.006 
Jung, J., Kim, M. Y., Lee, H. J., Park, Y. S., Lee, S. O., Choi, S. H., et al. (2015). Comparison of computed tomographic findings in pulmonary mucormycosis and invasive pulmonary aspergillosis. Clin. Microbiol. Infect. 21, 684-e11. doi: 10.1016/j.cmi.2015.03.019

Kang, S. H., Kim, M. Y., Eom, Y. W., and Baik, S. K. (2020). Mesenchymal stem cells for the treatment of liver disease: present and perspectives. Gut Liver 14, 306-315. doi: 10.5009/gnl18412

Kasai, M., Harrington, S. M., Francesconi, A., Petraitis, V., Petraitiene, R., Beveridge, M. G., et al. (2008). Detection of a molecular biomarker for zygomycetes by quantitative PCR assays of plasma, bronchoalveolar lavage, and lung tissue in a rabbit model of experimental pulmonary zygomycosis. J. Clin. Microbiol. 46, 3690-3702. doi: 10.1128/JCM.00917-08

Kasai, M., Harrington, S. M., Francesconi, A., Petraitis, V., Petraitiene, R., Beveridge, M. G., et al. (2008). Detection of a molecular biomarker for zygomycetes by quantitative PCR assays of plasma, bronchoalveolar lavage, and lung tissue in a rabbit model of experimental pulmonary zygomycosis. J. Clin. Microbiol. 46:3690. doi: 10.1128/JCM.00917-08

Krampera, M. (2011). Mesenchymal stromal cell'licensing': a multistep process. Leukemia 25, 1408-1414. doi: 10.1038/leu.2011.108

Kumar, P. V. R. (2020). COVID-19 cure through stem cells. J Regen Biol Med 2, 1-15. doi: 10.37191/Mapsci-2582-385X-2(3)-034

Lackner, M., Caramalho, R., and Lass-Flörl, C. (2014). Laboratory diagnosis of mucormycosis: current status and future perspectives. Future Microbiol. 9, 683-695. doi: $10.2217 /$ fmb.14.23

Larché, J., Machouart, M., Burton, K., Collomb, J., Biava, M. F., Gérard, A., et al. (2005). Diagnosis of cutaneous mucormycosis due to Rhizopusmicrosporus by an innovative PCR-restriction fragment-length polymorphism method. Clinical infect. dis. 41, 1362-1365. doi: 10.1086/497078

Lass-Flörl, C. (2009). Zygomycosis: conventional laboratory diagnosis. Clin. Microbiol. Infect. 5, 60-65. doi: 10.1111/j.1469-0691.2009.02999.x

Lass-Flörl, C., Resch, G., Nachbaur, D., Mayr, A., Gastl, G., Auberger, J., et al. (2007). The value of computed tomography-guided percutaneous lung biopsy for diagnosis of invasive fungal infection in immunocompromised patients. Clin. Infect. Dis. 45, e101-e104. doi: 10.1086/521245

Lathrop, M. J., Brooks, E. M., Bonenfant, N. R., Sokocevic, D., Borg, Z. D., Goodwin, M., et al. (2014). Mesenchymal stromal cells mediate aspergillus hyphal extract induced allergic airway inflammation by inhibition of the th17 signaling pathway. Stem Cells Transl. Med. 3, 194-205. doi: 10.5966/ sctm.2013-0061

Le Blanc, K., Frassoni, F., Ball, L., Soleimani, M., Vosough, M., Hosseini, S. E., et al. (2008). Mesenchymal stem cells for treatment of steroid-resistant, severe, acute graft-versus-host disease: a phase II study. Lancet 371, 15791586. doi: $10.1016 / S 0140-6736(08) 60690-\mathrm{X}$

Legouge, C., Caillot, D., Chrétien, M. L., Lafon, I., Ferrant, E., Audia, S., et al. (2014). The reversed halo sign: pathognomonic pattern of pulmonary mucormycosis in leukemic patients with neutropenia? Clin. Infect. Dis. 58, 672-678. doi: 10.1093/cid/cit929

Lepelletier, Y., Lecourt, S., Renand, A., Arnulf, B., Vanneaux, V., Fermand, J. P., et al. (2010). Galectin- 1 and semaphorin-3A are two soluble factors conferring T-cell immunosuppression to bone marrow mesenchymal stem cell. Stem Cells Dev. 19, 1075-1079. doi: 10.1089/scd.2009.0212

Li, Y., Ye, Z., Yang, W., Zhang, Q., and Zeng, J. (2021). An update on the potential of mesenchymal stem cell therapy for cutaneous diseases. Stem Cells Int. 2021:8834590. doi: 10.1155/2021/8834590

Liang, B., Chen, J., Li, T., Wu, H., Yang, W., Li, Y., et al. (2020). Clinical remission of a critically ill COVID-19 patient treated by human umbilical cord mesenchymal stem cells: A case report. Medicine 31:e21429. doi: 10.1097/MD.0000000000021429

Liu, Y., and Holmes, C. (2021). Tissue regeneration capacity of extracellular vesicles isolated From bone marrow-derived and adipose-derived mesenchymal stromal/stem cells. Front. Cell Dev. Biol. 9:648098. doi: 10.3389/fcell.2021.648098

Liu, M., Spellberg, B., Phan, Q. T., Fu, Y., Fu, Y., Lee, A. S., et al. (2010). The endothelial cell receptor GRP78 is required for mucormycosis pathogenesis in diabetic mice. J. Clin. Invest. 120, 1914-1924. doi: 10.1172/JCI42164

Liu, Y., Wu, H., Huang, F., Fan, Z., and Xu, B. (2013). Utility of 18F-FDG $\mathrm{PET} / \mathrm{CT}$ in diagnosis and management of mucormycosis. ClinNucl Med 38, e370-e371. doi: 10.1097/rlu.0b013e3182867d13

Ma, S., Xie, N., Li, W., Yuan, B., Shi, Y., and Wang, Y. (2014). Immunobiology of mesenchymal stem cells. Cell Death Differ. 21, 216-225. doi: 10.1038/ cdd.2013.158
Machouart, M., Larché, J., Burton, K., Collomb, J., Maurer, P., Cintrat, A., et al. (2006). Genetic identification of the main opportunistic Mucorales by PCR-restriction fragment length polymorphism. J. Clin. Microbiol. 44, 805-810. doi: 10.1128/JCM.44.3.805-810.2006

Mehta, S., and Pandey, A. (2020). Rhino-orbital mucormycosis associated with COVID-19. Cureus 12:e10726. doi: 10.7759/cureus.10726

Mekonnen, Z. K., Ashraf, D. C., Jankowski, T., Grob, S. R., Vagefi, M. R., Kersten, R. C., et al. (2020). Acute invasive rhino-orbital mucormycosis in a patient with COVID-19-associated acute respiratory distress syndrome. Ophthalmic Plast. Reconstr. Surg. 37, e40-e80. doi: 10.1097/ IOP.0000000000001889

Millon, L., Scherer, E., Rocchi, S., and Bellanger, A. P. (2019). Molecular Strategies to Diagnose Mucormycosis. J Fungi 5:24. doi: 10.3390/jof5010024

Nagao, K., Ota, T., Tanikawa, A., Takae, Y., Mori, T., Udagawa, S. I., et al. (2005). Genetic identification and detection of human pathogenic Rhizopus species, a major mucormycosis agent, by multiplex PCR based on internal transcribed spacer region of rRNA gene. J. Dermatol. Sci. 39, 23-31. doi: 10.1016/j.jdermsci.2005.01.010

Najar, M., Rouas, R., Raicevic, G., Boufker, H. I., Lewalle, P., Meuleman, N., et al. (2009). Mesenchymal stromal cells promote or suppress the proliferation of $\mathrm{T}$ lymphocytes from cord blood and peripheral blood: the importance of low cell ratio and role of interleukin-6. Cytotherapy 11, 570-583. doi: $10.1080 / 14653240903079377$

Nauta, A. J., and Fibbe, W. E. (2007). Immunomodulatory properties of mesenchymal stromal cells. Blood 110, 3499-3506. doi: 10.1182/ blood-2007-02-069716

Nick, H., Wong, A., Acklin, P., Faller, B., Jin, Y., Lattmann, R., et al. (2002). ICL670A: preclinical profile. InIron Chelation Therapy 509, 185-203. doi: 10.1007/978-1-4615-0593-8_10

Nyilasi, I., Papp, T., Csernetics, Á., Krizsán, K., Nagy, E., and Vágvölgyi, C. (2008). High affinity iron permease (FTR1) gene sequence based molecular identification of clinically important Zygomycetes. Clin. Microbiol. Infect. 14, 393-397. doi: 10.1111/j.1469-0691.2007.01932.x

Pittenger, M. F., Discher, D. E., Péault, B. M., Phinney, D. G., Hare, J. M., and Caplan, A. I. (2019). Mesenchymal stem cell perspective: cell biology to clinical progress. NPJ Regener. Med. 4, 86-86. doi: 10.1038/s41536-019-0083-6

Prakash, H., and Chakrabarti, A. (2019). Global epidemiology of Mucormycosis. J. Fungi 5:26. doi: 10.3390/jof5010026

Prakash, H., and Chakrabarti, A. (2021). Epidemiology of Mucormycosis in India. Microorganisms 9:523. doi: 10.3390/microorganisms 9030523

Prakash, H., Ghosh, A. K., Rudramurthy, S. M., Paul, R. A., Gupta, S., Negi, V., et al. (2016). The environmental source ofemerging Apophysomyces variabilis infection in India. Med. Mycol. 54, 567-575. doi: 10.1093/ mmy/myw014

Prakash, H., Singh, S., Rudramurthy, S. M., Singh, P., Mehta, N., Shaw, D., et al. (2020). An aero mycological analysis of Mucormycetes in indoor and outdoor environments of northern India. Med. Mycol. 58, 118-123. doi: 10.1093/mmy/myz031

Puerta-Arias, J. D., Pino-Tamayo, P. A., Arango, J. C., and González, Á. (2016). Depletion of neutrophils promotes the resolution of pulmonary inflammation and fibrosis in mice infected with Paracoccidioides brasiliensis. PLoS One 11:e0163985. doi: 10.1371/journal.pone.0163985

Qu, X., Liu, X., Cheng, K., Yang, R., and Zhao, R. C. (2012). Mesenchymal stem cells inhibit Th17 cell differentiation by IL-10 secretion. Exp. Hematol. 40, 761-770. doi: 10.1016/j.exphem.2012.05.006

Rafei, M., Campeau, P. M., Aguilar-Mahecha, A., Buchanan, M., Williams, P., Birman, E., et al. (2009). Mesenchymal stromal cells ameliorate experimental autoimmune encephalomyelitis by inhibiting CD4 Th17 T cells in a CC chemokine ligand 2-dependent manner. J. Immunol. 182, 5994-6002. doi: 10.4049/jimmunol.0803962

Raghav, A., Khan, Z. A., Upadhayay, V. K., Tripathi, P., Gautam, K. A., Mishra, B. K., et al. (2021). Mesenchymal stem cell-derived exosomes exhibit promising potential for treating SARS-CoV-2-infected patients. Cell 10:587. doi: $10.3390 /$ cells 10030587

Rahimkhoei, V., Jabbari, N., Nourani, A., Sharifi, S., and Akbari, A. (2021). Potential small-molecule drugs as available weapons to fight novel coronavirus (2019-nCoV): A review. Cell Biochem. Funct. 39, 4-9. doi: 10.1002/cbf.3576 Rasmusson, I., Ringdén, O., Sundberg, B., and Le Blanc, K. (2005). Mesenchymal stem cells inhibit lymphocyte proliferation by mitogens and alloantigens by 
different mechanisms. Exp. Cell Res. 305, 33-41. doi: 10.1016/j.yexcr.2004. 12.013

Ren, G., Su, J., Zhang, L., Zhao, X., Ling, W., L'huillie, A., et al. (2009). Species variation in the mechanisms of mesenchymal stem cell-mediated immunosuppression. Stem Cells 27, 1954-1962. doi: 10.1002/stem.118

Ren, G., Zhang, L., Zhao, X., Xu, G., Zhang, Y., Roberts, A. I., et al. (2008). Mesenchymal stem cell-mediated immunosuppression occurs via concerted action of chemokines and nitric oxide. Cell Stem Cell 2, 141-150. doi: 10.1016/j.stem.2007.11.014

Rizzo, R., Campioni, D., Rizzo, R., Campioni, D., Stignani, M., Melchiorri, L., et al. (2008). A functional role for soluble HLA-G antigens in immune modulation mediated by mesenchymal stromal cells. Cytotherapy 10, 364375. doi: 10.1080/14653240802105299

Roden, M. M., Zaoutis, T. E., Buchanan, W. L., Knudsen, T. A., Sarkisova, T. A., Schaufele, R. L., et al. (2005). Epidemiology and outcome of zygomycosis: a review of 929 reported cases. Clin. Infect. Dis. 41, 634-653. doi: 10.1086/432579

Salehi, M., Ahmadikia, K., Badali, H., and Khodavaisy, S. (2020). Opportunistic fungal infections in the epidemic area of COVID-19: A clinical and diagnostic perspective from Iran. Mycopathologia 185, 607-611. doi: 10.1007/ s11046-020-00472-7

Sarkar, S., Gokhale, T., Choudhury, S. S., and Deb, A. K. (2021). COVID-19 and orbital mucormycosis. Indian J. Ophthalmol. 69, 1002-1004. doi: 10.4103/ ijo.IJO_3763_20

Schmidt, S., Schneider, A., Demir, A., Lass Flörl, C., and Lehrnbecher, T. (2016). Natural killer cell mediated damage of clinical isolates of mucormycetes. Mycoses 59, 34-38. doi: 10.1111/myc. 12431

Schmidt, S., Tramsen, L., Schneider, A., Schubert, R., Balan, A., Degistirici, Ö., et al. (2017). Impact of human mesenchymal stromal cells on antifungal host response against aspergillus fumigatus. Oncotarget 8, 95495-95503. doi: 10.18632/oncotarget.20753

Sen, M., Lahane, S., Lahane, T. P., Parekh, R., and Honavar, S. G. (2021). Mucor in a viral land: A tale of two pathogens Indian. J. Ophthalmol. 69, 244-252. doi: 10.4103/ijo.IJO_3774_20

Singh, A. K., Singh, R., Joshi, S. R., and Misra, A. (2021). Mucormycosis in COVID-19: Asystematic review of cases reported worldwide and in India. Diabetes \& Metabolic Syndrome: Clinical Research \& Reviews. [Preprint]. doi:10.1016/j.dsx.2021.05.019

Sotiropoulou, P. A., Perez, S. A., Gritzapis, A. D., Baxevanis, C. N., and Papamichail, M. (2006). Interactions between human mesenchymal stem cells and natural killer cells. Stem Cells 24, 74-85. doi: 10.1634/stemcells.2004-0359

Springer, J., Lackner, M., Ensinger, C., Risslegger, B., Morton, C. O., Nachbaur, D., et al. (2016). Clinical evaluation of a Mucorales-specific real-time PCR assay in tissue and serum samples. J. Med. Microbiol. 65, 1414-1421. doi: 10.1099/ jmm.0.000375
Sugar, A. M. (2005). "Agents of mucormycosis and related species." in Principles and Practice of Infectious Diseases. 6th Edn. eds. G. L. Mandell, J. E. Bennett and R. Dolin, (Philadelphia, PA: Elsevier), 2979.

Vivier, E., Tomasello, E., Baratin, M., Walzer, T., and Ugolini, S. (2008). Functions of natural killer cells. Nat. Immunol. 9, 503-510. doi: 10.1038/ni1582

Waldorf, A. R., Levitz, S. M., and Diamond, R. D. (1984). In vivo bronchoalveolar macrophage defense against Rhizopus oryzae and aspergillus fumigatus. J. Infect. Dis. 150, 752-760. doi: 10.1093/infdis/150.5.752

Walsh, T. J., Goodman, J. L., Pappas, P., Bekersky, I., Buell, D. N., Roden, M., et al. (2001). Safety, tolerance, and pharmacokinetics of high-dose liposomal amphotericin B (AmBisome) in patients infected with aspergillus species and other filamentous fungi: maximum tolerated dose study. Antimicrob. Agents Chemother. 45:3487. doi: 10.1128/AAC.45.12.3487-3496.2001

Watkins, T. N., Gebremariam, T., Swidergall, M., Shetty, A. C., Graf, K. T., Alqarihi, A., et al. (2018). Inhibition of EGFR signaling protects from mucormycosis. MBio 9:e0184-18. doi: 10.1128/mBio.01384-18

Wu, F., Zhao, S., Yu, B., Chen, Y. M., Wang, W., Song, Z. G., et al. (2020). A new coronavirus associated with human respiratory disease in China. Nature 579, 265-269. doi: 10.1038/s41586-020-2008-3

Xue, Q., Luan, X. Y., Gu, Y. Z., Wu, H. Y., Zhang, G. B., Yu, G. H., et al. (2010). The negative co-signaling molecule B7-H4 is expressed by human bone marrow-derived mesenchymal stem cells and mediates its T-cell modulatory activity. Stem Cells Dev. 19, 27-38. doi: 10.1089/scd.2009.0076

Yang, R., Liu, Y., Kelk, P., Qu, C., Akiyama, K., Chen, C., et al. (2013). A subset of IL-17+ mesenchymal stem cells possesses anti-Candida albicans effect. Cell Res. 23, 107-121. doi: 10.1038/cr.2012.179

Conflict of Interest: The authors declare that the research was conducted in the absence of any commercial or financial relationships that could be construed as a potential conflict of interest.

Publisher's Note: All claims expressed in this article are solely those of the authors and do not necessarily represent those of their affiliated organizations, or those of the publisher, the editors and the reviewers. Any product that may be evaluated in this article, or claim that may be made by its manufacturer, is not guaranteed or endorsed by the publisher.

Copyright (c) 2021 Raghav, Ali, Jeong, Gautam, Banday, Mateen, Tripathi, Giri, Agarwal, Singh and Khan. This is an open-access article distributed under the terms of the Creative Commons Attribution License (CC BY). The use, distribution or reproduction in other forums is permitted, provided the original author $(s)$ and the copyright owner(s) are credited and that the original publication in this journal is cited, in accordance with accepted academic practice. No use, distribution or reproduction is permitted which does not comply with these terms. 